\title{
АНАЛИЗ ОСОБЕННОСТЕЙ ИЗМЕНЧИВОСТИ ОСНОВНЫХ ГЕОЛОГО-ПРОМЫШЛЕННЫХ ПАРАМЕТРОВ ЛЕНИНГРАДСКОГО МЕСТОРОЖДЕНИЯ ГОРЮЧИХ СЛАНЦЕВ
}

Фактический материал, накопившийся за тридцатилетнюю историю разведки и эксплуатации Ленинградского месторождения горючих сланцев, позволяет достаточно полно охарактеризовать особенности изменчивости его основных геолого-промышленных параметров (мощности, качества и условий залегания промышленного пласта горючих сланцев). Эта характеристика может явиться полезной основой для разработки рациональной методики разведки месторождения и для оценки достоверности результатов геолого-разведочных работ.

\section{Изменчивость мощности и основных качественных показателей промышленного пласта горючих сланцев *}

Промышленный пласт горючих сланцев в пределах Ленинградского месторождения имеет выдержанную мощность и строение (рис. 1). Закономерное уменьшение мощности отдельных слоев сланца происходит
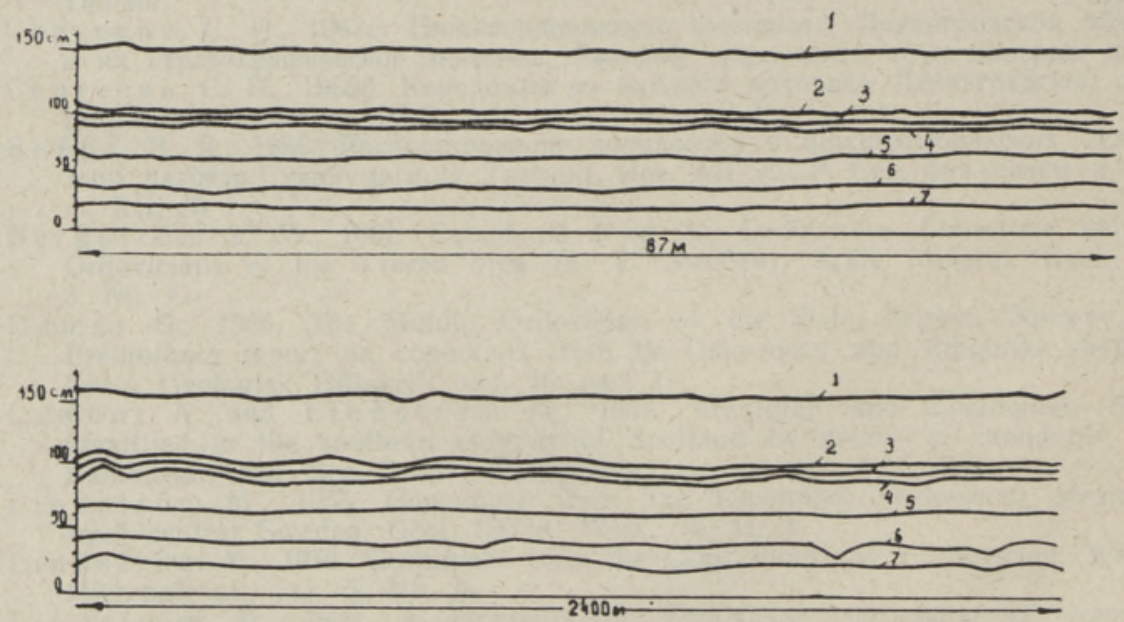

Рис. 1. Изменение мощности слоев промышленной пачки горючих сланцев: 1 - изменение мощности 1-го слоя сланца; 2 - измененне мощности разделяющего прослоя нзвестняка «плита»; 3 - изменение мощности мергелистого сланца; 4 - изменение мощносги прослоя известняка жрозовая плита»; 5 - изменение мощности 2-го слоя сланца: 6 - изменение мощности прослоя известняка «кулак»; $7-$ изменение мощности 3-го слоя сланца.

* При составлении этого раздела частично использованы материалы А. С. Левина и С. В. Парадеева. 
с запада на восток и с севера на юг на 0,5-1,0 cм на каждые $5 \kappa \mu$. Согласно классификации Е. О. Погребицкого [5], по этому признаку месторождение относится к группе очень устойчивых.
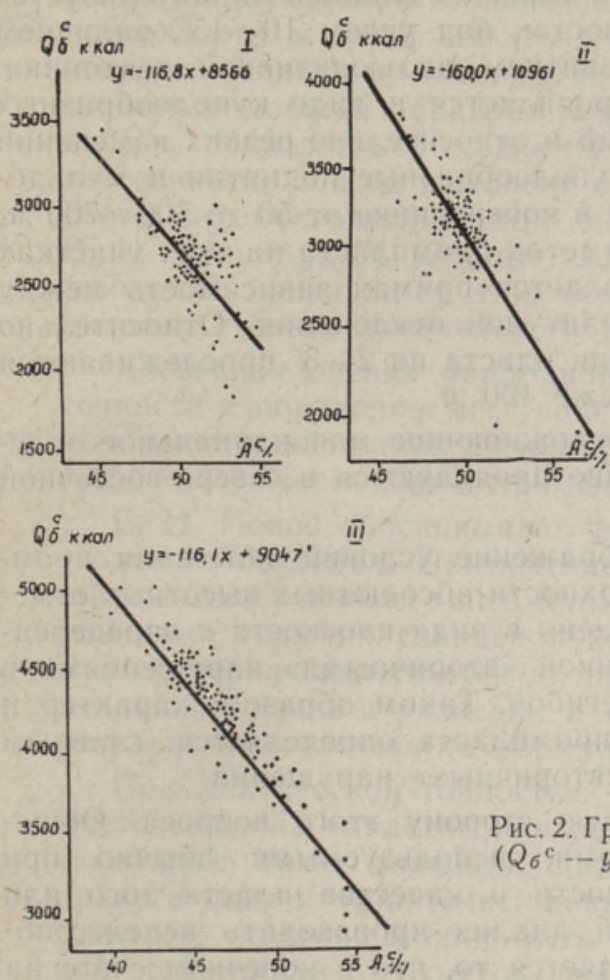

Рис. 2. График зависимости теплотворной способности $\left(Q_{6}{ }^{\mathrm{c}}-y\right)$ горючего сланца от зольности $\left(A^{\mathrm{c}}-x\right)$ : чества горючего сланца являются теплотворная способность $\left(Q_{\sigma}{ }^{\mathrm{c}}\right)$ и зольность $\left(A^{\mathrm{c}}\right)$. Теплотворная способность сланца закономерно увеличивается по разрезу пласта сверху вниз и по простиранию с севера на юг, а также в меньшей степени с запада на восток. По численной оценке степени изменчивости теплотворной способности и зольности отдельных слоев сланца месторождение относится к группе весьма равномерных $(V=0 \div 20 \%)[3]$.

Как показывают расчеты, между теплотворной способностью и зольностью сланца существует обратная пропорциональная зависимость (табл. 1, рис. 2).

Основными показателями ка-

Таблица

Значения коэффициента корреляции $\left(Q_{5}\right.$ и $A$ c)

и уравнения регрессии

\begin{tabular}{|c|c|c|c|c|c|c|}
\hline \multirow{3}{*}{ 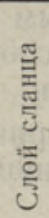 } & \multicolumn{5}{|c|}{$\begin{array}{c}\text { Данные, принятые при расчете } \\
\text { уравнения регрессии }\end{array}$} & \multirow{3}{*}{$\begin{array}{l}\text { Уравнение } \\
\text { регрессии * }\end{array}$} \\
\hline & \multicolumn{2}{|c|}{$\begin{array}{c}\text { Теплотворная } \\
\text { способность, } \\
\kappa \kappa a л \\
\end{array}$} & \multicolumn{2}{|c|}{$\begin{array}{c}\text { Зольность, } \\
\%\end{array}$} & \multirow{2}{*}{$\begin{array}{l}\text { Коеффи- } \\
\text { циент } \\
\text { корреля- } \\
\text { ции }\end{array}$} & \\
\hline & средняя & $\sigma$ & средняя & $\sigma$ & & \\
\hline 1 & 2703 & $226, \overline{5}$ & 50,2 & 2,1 & $-0,92$ & $\begin{aligned} y= & -116,8 x+ \\
& +8566\end{aligned}$ \\
\hline 2 & 3093 & 350,0 & 49,3 & 2,1 & $-0,96$ & $y=\frac{-160,0 x+}{+}$ \\
\hline 3 & 4253 & 366,1 & 41,3 & 2,9 & $-0,92$ & $\begin{aligned} y= & -116,1 x+ \\
& +9047\end{aligned}$ \\
\hline
\end{tabular}

без $\mathrm{CO}_{2}$ ) 


\section{Изменчивость гипсометрии промышленного пласта горючих сланцев}

Залегание промышленного пласта горючих сланцев характеризуется спокойным падением на юг и юго-восток под углом $10-15^{\prime}$, наличием волнистости и незначительным развитием дизъюнктивной тектоники. Волнистое залегание промпласта проявляется в виде куполообразных поднятий, мульдообразных понижений и относительно резких изменений элементов залегания промпласта. Куполообразные поднятия и мульдообразные понижения имеют размеры в поперечнике от 50 до 500-700 $\mathrm{M}$; отклонения абсолютных высотных отметок промпласта на этих участках изменяются от 0,3 до 3,0 м. Наблюдается прямая зависимость между их размерами в поперечнике и амплитудой отклонения. Относительно резкие изменения элементов залегания пласта на $2-3^{\circ}$ прослеживаются на протяжении обычно 50-100 и реже 400 м.

Описанные вторичные явления, осложняющие моноклинальное залегание промпласта, наиболее отчетливо проявляются в северо-восточной и восточной частях месторождения.

Следовательно, графическое изображение условий залегания промпласта в виде топографической поверхности абсолютных высотных отметок его почвы может быть представлено в виде плоскости с определенным небольшим наклоном, осложненной «вторичными» нарушениями в виде впадин, куполов и резких перегибов. Таким образом, характер и степень изменчивости гипсометрии промпласта определяется, главным образом, количеством и размером «вторичных» нарушений.

Рассмотрим теперь количественную сторону этого вопроса. Общегринятыми аналитическими способами, используемыми обычно при оценке степени изменчивости мощности и качества пласта того или иного полезного ископаемого, такой анализ производить нецелесообразно. Общим для этих методов является то, что в конечном счете на их основании определяется рассеивание результатов замеров геологических параметров относительно среднего. Гипсометрия же является специфическим свойством месторождения. В отличие от мощности и качества она оценивается не средней величиной высотных отметок, а топографической поверхностью. Следовательно, нас интересует не погрешность определения среднего, а точность топографической поверхности абсолютных высотных отметок, построенной по данным того или иного количества разведочных выработок, т. е. степень соответствия такой топографической поверхности истинной форме залежи.

Для численной оценки степени изменчивости гипсометрии залежи может быть использован метод Е. И. Попова [], предложившего формулу

$$
\sigma= \pm \sqrt{\frac{\Sigma K^{2}}{4 \kappa}}
$$

где $\sigma$-, средняя квадратичная ошибка определения абсолютных высотных отметок почвы (кровли) залежи по ее гипсометрическому плану, или численная оценка степени ее изменчивости, $м$; $K=\left[\left(h_{1}+h_{3}\right)-\left(h_{2}+h_{4}\right)\right]$, где $h_{1}, h_{2}, h_{3}, h_{4}$ - последовательные значения абсолютных высотных отметок почвы (кровли) залежи по точкам разведочной ячейки, в которой производилась интерполяция, $м$;

$\kappa$-.. число значений $K$. 
Е. И. Попов исходит из относительности понятия «изменчивость», рассматривая его как результат наших знаний о свойствах изучаемого. объекта. Такой подход позволяет считать точность графического изображения изучаемого геологического параметра в виде топографической поверхности ме рой его изменчивости. А поскольку точность, в первую очередь, зависит от количества наблюдений, то и изменчивость, понимаемая подобным образом, также зависит от этого фактора. Следовательно, показатель $\sigma$ является численной мерой точности построения гипсометрии залежи и степени ее изменчивости на данном этапе изученности. Это обстоятельство не было учтено в работе В. Н. Зарайского и В. И. Кузьмина $\left[{ }^{2}\right]$, которые, доказав зависимость $\sigma$ от количества наблюдений, признали на этом основании формулу (1) неприемлемой для анализа степени изменчивости геологических параметров.

Косвенная оценка природной степени изменцивости гипсометрии по точности изображения ее в виде топографической поверхности абсолютных высотных отметок почвы (кровли) залежи вполне правомочна, в связи с чем возможно и применение для этой цели формулы (1).

Е. И. Попов обосновывает формулу (1) на примере Подмосковного угольного бассейна. Применение ее для оценки точности построения и степени изменчивости гипсометрии промпласта на Ленинградском месторождении горючих сланцев нуждается в экспериментальной проверке. Эта проверка заключается в определении фактической точности гипсометрии по данным разведки и в сравнении полученных результатов с результатами расчета по формуле (1).

Под фактической точностью гипсометрического плана залежи понимается ошибка аналогии или ошибка интерполяции, т. е. измеренные в какой-либо точке значения показателя распространяются на участки, прилегающие к этой точке. Таким образом, фактическая точность гипсометрии численно может быть выражена отклонением отметок истинной поверхности от отметок, снятых с гипсометрического плана, и рассчитана по следующей формуле:

$$
\sigma_{\phi}= \pm \sqrt{\frac{\Sigma\left(h_{i}-h_{\phi}\right)^{2}}{n}}
$$

где $\sigma_{\Phi}-$ фактическая средняя квадратичная ошибка определения отметок почвы (кровли) залежи по ее гипсометрическому плану, построенному по данным разведки, $м$;

$h_{i}$ - среднее арифметическое из четырех значений отметок подошвы (кровли) залежи в разведочной ячейке, м;

$h_{\text {ф }}$ - фактическая отметка в центре разведочной ячейки, снятая с плана, $м$;

$n$ - число разведочных ячеек.

В связи с тем, что результаты геолого-разведочных работ по месторождению содержат значительные технические ошибки при определении абсолютных высотных отметок подошвы промпласта по скважинам, для решения поставленной задачи используем данные маркшейдерского гипсометрического плана одного из шахтных полей месторождения, как наиболее точно отражающие особенности залегания промпласта. Эти данные можно принять условно за результаты экспериментальной разведки. Для этого гипсометрический план разбивается на квадраты со стороной $125 \mu$ в соответствии с масштабом плана; в углах квадратов, полученных на плане, определяются абсолютные высотные отметки подошвы 
промпласта. Определение фактической точности построения гипсометрии по формуле (2) и оценка точности по формуле (1) производились по сеткам $125 \times 125 \mu$ (одно положение), $250 \times 250 \mu$ (четыре положения), $500 \times 500 м$ (шестнадцать положений) и $1000 \times 1000$ м (шестнадцать положений). Пример расчета для одного положения сети скважин приведен в табл. 2. Результаты расчета в виде средних значений $\sigma$ и $\sigma_{\Phi}$ из всех положений для одной плотности сети приведены в табл. 3.

Сопоставление рассчитанных значений $\sigma$ и $\sigma_{\phi}$ показывает хорошую

Таблица 2

Расчет фактической точности гипсометрии $\left(\sigma_{\phi}\right)$ и оценка точности ее построения $(\sigma)$ по сетке $500 \times 500 \mu$

\begin{tabular}{|c|c|c|c|c|c|c|c|c|c|c|c|}
\hline$=$ & $=$ & $\|_{0}^{5}=$ & $\approx$ & $\Xi$ & $\begin{array}{r}= \\
+ \\
0= \\
0\end{array}$ & $\begin{array}{c}11 \\
=+ \\
=-0 \\
\mid 1\end{array}$ & $\approx$ & $\begin{array}{l}= \\
=\end{array}$ & $\begin{array}{l}\stackrel{5}{E} \\
5\end{array}$ & $<$ & 2 \\
\hline \multirow[t]{2}{*}{$\begin{array}{l}21,0 \\
22,8 \\
25,3 \\
26,5 \\
21,9 \\
24,4 \\
26,8 \\
29,6 \\
25,5 \\
27,2 \\
28,8 \\
30,4 \\
25,3 \\
27,9 \\
29,0 \\
31,4 \\
28,0 \\
29,0 \\
30,6 \\
31,3\end{array}$} & $\begin{array}{l}24,4 \\
26,8 \\
29,6 \\
31,2 \\
27,2 \\
28,8 \\
30,4 \\
30,8 \\
27,9 \\
29,0 \\
31,4 \\
32,6 \\
29,0 \\
30,6 \\
31,3 \\
34,0 \\
30,5 \\
30,8 \\
30,0 \\
33,5\end{array}$ & $\begin{array}{l}45,4 \\
49,6 \\
54,9 \\
57,7 \\
49,1 \\
53,2 \\
57,2 \\
60,4 \\
53,4 \\
56,2 \\
60,2 \\
63,2 \\
54,3 \\
58,5 \\
60,3 \\
65,4 \\
58,5 \\
59,8 \\
60,6 \\
64,8\end{array}$ & $\begin{array}{l}22,8 \\
25,3 \\
26,5 \\
29,6 \\
24,4 \\
26,8 \\
29,6 \\
31,2 \\
27,2 \\
28,8 \\
30,4 \\
30,8 \\
27,9 \\
29,0 \\
31,4 \\
32,6 \\
29,0 \\
30,6 \\
31,3 \\
34,0\end{array}$ & $\begin{array}{l}21,9 \\
24,4 \\
26,8 \\
29,6 \\
25,5 \\
27,2 \\
28,8 \\
30,4 \\
25,3 \\
27,9 \\
29,0 \\
31,4 \\
28,0 \\
29,0 \\
30,6 \\
31,3 \\
29,0 \\
30,5 \\
30,8 \\
30,0\end{array}$ & $\begin{array}{l}44,7 \\
49,7 \\
53,3 \\
59,2 \\
49,9 \\
54,0 \\
58,4 \\
61,6 \\
52,5 \\
56,7 \\
59,4 \\
62,2 \\
55,7 \\
58,0 \\
62,0 \\
63,9 \\
58,0 \\
61,1 \\
62,1 \\
64,0\end{array}$ & $\begin{array}{l}22,25 \\
24,82 \\
27,05 \\
29,22 \\
24,75 \\
26,80 \\
28,90 \\
30,50 \\
26,98 \\
28,22 \\
29,90 \\
31,35 \\
27,55 \\
29,12 \\
30,60 \\
32,30 \\
29,12 \\
30,22 \\
30,70 \\
32,2\end{array}$ & $\begin{array}{l}22,7 \\
24,0 \\
27,0 \\
28,5 \\
24,5 \\
26,8 \\
29,6 \\
30,6 \\
26,0 \\
28,9 \\
23,7 \\
31,3 \\
27,4 \\
28,5 \\
31,1 \\
33,4 \\
29,2 \\
30,0 \\
31,5 \\
33,3\end{array}$ & $\begin{array}{r}-0,45 \\
+0,82 \\
+0,05 \\
+0,72 \\
+0,25 \\
0,0 \\
-0,7 \\
-0,1 \\
+0,98 \\
-0,68 \\
+1,2 \\
+0,05 \\
+0,15 \\
+0,62 \\
-0,5 \\
-0,9 \\
-0,08 \\
+0,22 \\
-0,8 \\
-1,1\end{array}$ & $\begin{array}{l}0,20 \\
0,67 \\
0,1 \\
0,51 \\
0,06 \\
0,0 \\
0,49 \\
0,01 \\
0,96 \\
0,46 \\
1,44 \\
0,0 \\
0,03 \\
0,38 \\
0,25 \\
0,81 \\
0,01 \\
0,48 \\
0,64 \\
1,21\end{array}$ & $\begin{array}{l}0,7 \\
0,1 \\
1,6 \\
1,5 \\
0,8 \\
0,8 \\
1,2 \\
1,2 \\
0,9 \\
0,5 \\
0,8 \\
1,0 \\
1,6 \\
0,5 \\
1,7 \\
1,5 \\
0,5 \\
1,3 \\
1,5 \\
0,8\end{array}$ & $\begin{array}{l}0,49 \\
0,01 \\
2,56 \\
2,25 \\
0,64 \\
0,64 \\
1,44 \\
1,44 \\
0,81 \\
0,25 \\
0,64 \\
1,0 \\
2,56 \\
0,25 \\
2,39 \\
2,25 \\
0,25 \\
1,69 \\
2,25 \\
0,64\end{array}$ \\
\hline & & & & & $n$ & & $\frac{8,61}{20}$ & & 8,61 & & 24,92 \\
\hline
\end{tabular}

Таблица 3

Сопоставление средних значений $\sigma$ и $\sigma_{\Phi}$

\begin{tabular}{c|c|c}
\hline $\begin{array}{c}\text { Плотность } \\
\text { разведочной } \\
\text { сети, } \mu\end{array}$ & $\begin{array}{c}\text { Фактическая } \\
\text { точность } \\
\text { гипсометрии } \\
\sigma_{\text {ф, } \mu}\end{array}$ & $\begin{array}{c}\text { Оценка } \\
\text { точности } \\
\sigma, \mu\end{array}$ \\
\hline $125 \times 125$ & 0,21 & 0,23 \\
$250 \times 250$ & 0,40 & 0,41 \\
$500 \times 500$ & 0,58 & 0,60 \\
$1000 \times 1000$ & 0,92 & 0,93
\end{tabular}

сходимость их, что говорит о возможности использования формулы (1) для численной оценки точности гипсометрии промпласта по данным разведки. В отношении оценки степени изменчивости гипсометрии промпласта значения показателя $\sigma$ имеют следующий смысл: природная степень изменчивости условий залегания промпласта такова, что при изображении их в виде топографической поверхности абсолют-

ных высотных отметок подошвы по данным разведки по сети, к примеру, $250 \times 250$, может быть достигнуто одно конкретное значение точности, 
в то время как при разведке по сети меньшей плотности точность построения гипсометрии, соответственно, уменьшается и наоборот. Это положение иллюстрируется графиком зависімости точности построения гипсометрии от плотности разведочной сети по данным расчета $\sigma$ и $\sigma_{\Phi}$ (рис. 3 ); одновременно этот график показывает зависимость точности построения гипсометрии промпласта от степени ее изменчивости.

Анализ точности построенных по данным разведки гипсометрических планов дает возможность более эффективно осуществлять проведение эксплуатационных работ и проектирование горнодобывающих предприятий.

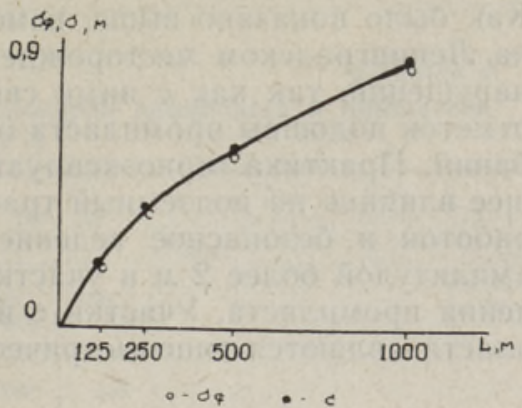

$\sigma_{\phi}-$ фактическая точность гипсометрни; $\quad \sigma-$ численная оценка точности гипсометрии по формуле (1).

Рис. 3. График зависимости точности построения гипсометрии промпласта по сеткам различной плотности по результатам экспериментальной разведки. Одновременно представляется возможность производить обоснование рациональной методики разведочных работ в зависимости от степени изменчивости залегания промпласта.

Учитывая важность условий залегания промпласта для оценки Ленинградского месторождения горючих сланцев, нельзя ограничиться лишь косвенной численной оценкой степени их изменчивости по точности построения гипсометрических планов. Для разработки методики разведки необходимо установить, к какой группе относится месторождение по степени изменчивости условий залегания, а также проследить особенность проявления изменчивости этого геологического параметра по площади. С этой целью воспользуемся методом, предложенным В. С. Огарковым [ $\left.{ }^{4}\right]$.

Этот метод разработан на примере Подмосковского угольного бассейна и рекомендуется к использованию при аналитической оценке особенностей изменчивости геологических свойств на месторождениях платформенного типа, характеризующихся горизонтальным или слабо наклонным залеганием тела полезного ископаемого, пластообразной или линзообразной формой залежи, большой протяженностью залежи по площади и незначительным развитием дизъюнктивной тектоники. Для Ленинградского месторождения горючих сланцев этот метод применим, поскольку ему свойственны отмеченные выше особенности.

Устойчивость месторождения, согласно В. С. Огаркову, определяется по формуле

$$
P_{1}=\frac{s_{1}}{S},
$$

где $P_{1}$ - показатель устойчивости месторождения;

$s_{1}$ - сумммарная площадь «аномалий» - участков, на которых изменчивость природных свойств выражена наиболее резко, тыс. $M^{2}$;

$S-$ площадь месторождения, тыс. $M^{2}$.

Прежде чем определить показатель устойчивости по гипсометрии для Ленинградского месторождения, необходимо установить, какие величины отклонений абсолютных высотных отметок подошвы промпласта следует считать аномальными, а какие нет. Критерием для этого служит степень влияния их колебания на проведение горнодобычных работ. 
Как было показано выше, изменчивость условий залегания промпласта на Ленинградском месторождении определяется наличием «вторичных» нарушений, так как с ними связаны отклонения абсолютных высбтных отметок подошвы промпласта от средних значений и пределы этих колебаний. Практика горноэксплуатационных работ показала, что наибольшее влияние на подземный транспорт, водоотлив, крепление горных выработок и безопасное ведение работ оказывают мульды и купола с амплитудой более 2 м и участки с относительно резким изменением падения промпласта. Участки с изложенными условиями залегания промпласта являются гипсометрически аномальными.

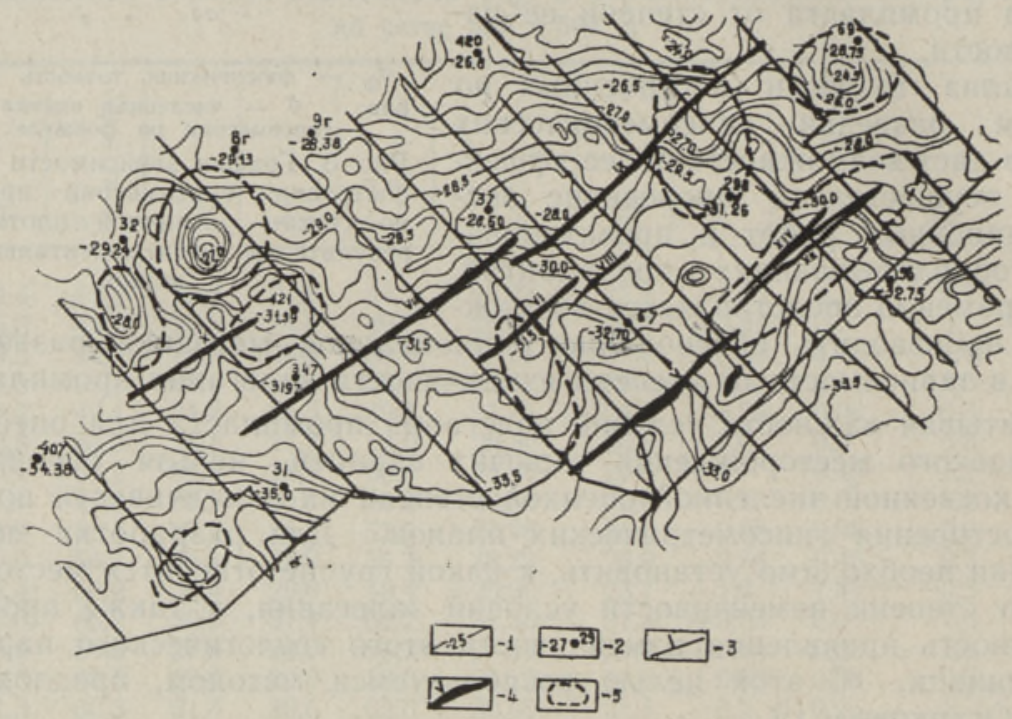

Рис. 4. Гипсометрия подошвы промпласта горючих сланщев с выделенными аномальными зонами:

I ... изогипсы подошвы промпласта; 2 - скважина, ее номер и абсолютная высотная отметка подошвы промпласта; 3 - горные выработки; 4 - карстовые нарушения в промпласте и их номер; 5 - аномалии по гипсометрии.

Аномальные по гипсометрии участки выявлялись и оконтуривались на маркшейдерских планах, примером чему является рис. 4. Суммарные площади, занимаемые гипсометрически аномальными участками, приведены в табл. 4.

Размещение гипсометрических аномальных участков по отдельным шахтным полям и в целом по месторождению не подчиняется определенной закономерности. В некоторых случаях может быть отмечена приуроченность их к зонам трещиноватости северо-восточного простирания, что определяет их в преобладающем северо-восточное направление. Большинство гипсометрически аномальных участков имеет размеры в поперечнике $500-600$ м. Форма их овальная, изометрическая.

При группировке гипсометрически аномальных участков по размеру в поперечнике $(400 \div 500,500 \div 600,600 \div 700$ м) устанавливается зависимость между суммарными площадями каждой из групп этих участков.

$$
s_{1}: s_{2}: s_{3}=1: 1,5: 3,
$$

где $s_{1}, s_{2}, s_{3}$ - суммарные площади аномальных участков по гипсометрии в тыс. $M^{2}-$ соответственно по группам размеров в поперечнике $-400 \div 500,500 \div 600,600 \div 700$ м (см. табл. 4). 
Таó.лицุa 4

Суммарные площади аномальных зон по гипсометрии промпласта и показатель устойчивости $\left(P_{1}\right)$

\begin{tabular}{|c|c|c|c|c|c|c|c|c|c|c|c|}
\hline \multirow[b]{2}{*}{$\begin{array}{c}\text { Нанмено- } \\
\text { ванне } \\
\text { шахтного } \\
\text { поля }\end{array}$} & \multirow{2}{*}{$\begin{array}{c}\text { Размер } \\
\text { аномалиі } \\
\text { в none- } \\
\text { речнике, } \\
\text { }\end{array}$} & \multicolumn{2}{|c|}{$400-500$} & \multicolumn{2}{|c|}{$500-600$} & \multicolumn{2}{|c|}{$600-700$} & \multirow{2}{*}{$\begin{array}{c}\text { Cвыне } \\
700\end{array}$} & \multirow{2}{*}{$\begin{array}{c}\text { Сум- } \\
\text { марная } \\
\text { пло- } \\
\text { щадь; }\end{array}$} & \multirow{2}{*}{$\begin{array}{c}\text { Пло- } \\
\text { щадь } \\
\text { пахтного } \\
\text { поля. } \\
\text { с. }{A^{2}}^{2}\end{array}$} & \multirow{2}{*}{$\begin{array}{l}\text { Пока- } \\
\text { затель } \\
\text { устой- } \\
\text { чнвости } \\
P_{1}\end{array}$} \\
\hline & & $\frac{400-}{450}$ & $\begin{array}{c}450- \\
500 \\
1\end{array}$ & $\begin{array}{r}500 \\
\quad 550\end{array}$ & $\begin{array}{r}550 \\
600\end{array}$ & $\frac{600}{650}$ & $\begin{array}{r}650 \\
700\end{array}$ & & & & \\
\hline $\begin{array}{l}\text { Шахтное } \\
\text { поле } \mathcal{N}_{2} 1\end{array}$ & $\begin{array}{c}\text { Площадь } \\
\text { аномалий, } \\
\text { тыс. } s^{2}\end{array}$ & 100 & 112 & 150 & 185 & $\begin{array}{r}240 \\
\end{array}$ & 370 & - & -1157 & 9080 & 0.17 \\
\hline $\begin{array}{l}\text { Шахтное } \\
\text { поле N.2 }\end{array}$ & $\begin{array}{c}\text { Площадь } \\
\text { апомалиё, } \\
\text { тыс. } \mu^{2}\end{array}$ & - & 275 & 165 & 240 & 325 & 530 & 405 & 1940 & 10620 & 0.18 \\
\hline $\begin{array}{l}\text { IHaxtное } \\
\text { поле № } 3\end{array}$ & $\begin{array}{c}\text { Площадь } \\
\text { аномалий, } \\
\text { тыс. } M^{3}\end{array}$ & 70 & 112 & 125 & 138 & 150 & 405 & & 1000 & 5350 & 0,19 \\
\hline $\begin{array}{l}\text { Шахтное } \\
\text { поле им. } \\
\text { Кирова }\end{array}$ & $\begin{array}{c}\text { Площадь } \\
\text { амомалиї. } \\
\text { тыс. } s^{2}\end{array}$ & & 135 & 100 & 115 & - & 380 & & 730 & 5030 & 0,14 \\
\hline $\begin{array}{l}\text { Ленин- } \\
\text { градское } \\
\text { место- } \\
\text { рождение }\end{array}$ & $\begin{array}{l}\text { Плоцадь } \\
\text { аномалиян, } \\
\text { тыс. } \mathrm{M}^{2}\end{array}$ & 170 & 634 & 540 & 678 & 715 & 1685 & 405 & 4827 & 28400 & 0.17 \\
\hline
\end{tabular}

В табл. 4 приведены также результаты расчета показателя устойчнвости по гипсометрии $-P_{1}$ по формуле (3). В целом по месторождению показатель устойчивости по гипсометрии составляет 0,17 ; наблюдается тенденция его увеличения с запада на восток и с севера на юг.

Согласно классификации В. С. Огаркова [4], Ленинградское месторождение по условиям залегания промпласта может быть отнесено к группе относительно устойчивых; которая характеризуется, $P_{1}=0,25$.

Определение общего, количества и распределения гипсометрически аномальных участков по гипсометрии, дополненное оценкой точности построения гипсометрических планов по сеткам различной плотности, всесторонне характеризует особенности изменчивости залегания промпласта и тем самым дает возможность установить условия разведки месторождения.

\section{Л И Т Е Р А У РА}

1. Богацкий В. В., Математическнй анализ разеедочной сети, М., 1963.

2. 3 а р а й ский В. Н., Қ у з ми н В. М., К определению изменчивости показателей месторождений с помощью вторых разностей, Изв. вузов. Геология и разведка, № $1,1965$.

3. К рейтер В. М., Поиски и разведка месторождений полезных ископаемых, М.. 1961 .

4. Огарков В. С., Методика разведки угольных месторождений платформенного типа, М., 1961.

5. Погреби цки й Е. О., Геолого-промышленная классификация месторождений ископаемых углей, Тр. лабор. геол. угля АН СССР, вып. 5, 1956.

6. По по в Е. И., К оценке точности изображения залежи полезного ископаемого по данным разведки, Зап. Ленингр. горн. ин-та, 1959.

7. У ш а ков И. Н., Горная геометрия, М., 1962.

Ленинарадский сорный институт 
A. ZOSIN

\section{LENINGRADI POLEVKIVIMAARDLA PEAMISTE GEOLOOGILISTE TOOTMISPARAMEETRITE MUUTLIKKUSE ANALOOS}

Leningradi põlevkivileiukohas määrab geoloogiliste uuringute ratsionaalse metoodika pōhiliselt tootsa kihi paksuse, kvaliteedi ja hüpsomeetria muutlikkus.

Tootsa kihi paksuse ja kvaliteedi muutlikkuse poolest võib leiukohta pidada eriti ühtlaseks, tema hüpsomeetria muutlikkuse järgi aga suhteliselt püsivaks.

Lasumustingimuste järgi eraldatakse uuritud leiukohas anomaalsed alad, kirjeldatakse nende kuju, suurust ning selgitatakse leviku seaduspärasused.

A. ZYSIN

\section{AN ANALYSIS OF THE VARIATION OF THE MAIN GEOLOGICAL PRODUCTION PARAMETRES OF LENINGRAD OIL SHALE DEPOSITS}

The variation of the thickness, quality and gypsometry of the subface of the productive oil shale (kukersite) strata in the Leningrad Region stipulates an elaboration and choice of rational methods of geological exploration.

According to the variation of the thicknesses of the productive strata, the Leningrad deposit belongs to the group of considerably uniform ones, and according to the variation in gypsometry - to the group of relatively stable ones. The sections containing anomalies in the gypsometry of the subface of productive strata are defined, their configuration and dimensions are described, and the regularities in their distribution are stated. 